\title{
Low Flow Venoarterial ECMO Support Management in Postcardiac Surgery Patient
}

\author{
Ritu Airan ${ }^{1}$ Sandeep Sharan ${ }^{2}$ Poonam Malhotra Kapoor ${ }^{2} \quad$ Ujjwal Chowdhury $^{3}$ \\ V. Devagourou ${ }^{3}$ Archip John ${ }^{1}$ \\ ${ }^{1}$ Department of Perfusion, AlIMS, New Delhi, India \\ 2Department of Cardiac Anaesthesia, CTC, AlIMS, New Delhi, \\ India52103107 \\ ${ }^{3}$ Department of CTVS, CTC, AlIMS, New Delhi, India

\begin{abstract}
Address for correspondence Poonam Malhotra Kapoor, MD. DNB MNAMS, FIACTA (Hony), FTEE (Hony), FISCU (Hony) Department of Cardiac Anaesthesia, CTC, AlIMS, New Delhi 110029, India
\end{abstract} \\ (e-mail: drpoonamaiims@gmail.com).
}

J Card Crit Care 2021;5:103-107.

\begin{abstract}
Keywords

- Low-flow ECMO

- postcardiac patient

- VA-VV ECMO

Venoarterial extracorporeal membrane oxygenation (VA ECMO) aims to fully support heart and lung function in postcardiac patients, ensuring end-organ perfusion and allowing time for possible heart recovery. VA ECMO is considered the modified and extended form of cardiopulmonary bypass (CPB), which is used to provide adequate tissue oxygenation. ECMO and the associated management protocols will mechanically support the patient and allow for the optimization of all aspects of care for the period of time necessary for the recovery of native cardiac or respiratory function. Significant technical advancements have been made in the equipment and the clinical management available for short- and long-term ECMO application. There are various parameters that have to be considered to evaluate whether the level of perfusion in patients on VA ECMO is adequate, and the outcomes of patients depend on them.
\end{abstract}

\section{Introduction}

Venoarterial extracorporeal membrane oxygenation (VA ECMO) aims to fully support heart and lung function in postcardiac patients, ensuring end-organ perfusion and allowing time for possible heart recovery. VA ECMO is considered the modified and extended form of cardiopulmonary bypass ( $\mathrm{CPB})$, which is used to provide adequate tissue oxygenation. ECMO and the associated management protocols will mechanically support the patient and allow for the optimization of all aspects of care for the period of time necessary for the recovery of native cardiac or respiratory function. Significant technical advancements have been made in the equipment and the clinical management available for shortand long-term ECMO application. There are various parameters that have to be considered to evaluate whether level of perfusion in patients on VA ECMO is adequate, and the outcomes of patients depend on them. ${ }^{1,2}$
Low-flow ECMO is one of the parameters on which with the adequacy of perfusion and outcome of the patient depends. The regulation of ECMO flows is an awkward process in which the need to ensure an adequate end-organ perfusion, especially during the first phase of resuscitation and stabilization, could conflict with the inherent risk of increased left ventricular afterload. Indeed, the attempt to maximize end-organ perfusion during the immediate postimplantation phase with high VA ECMO flow is not without risk.

According to the ELSO guidelines, veno arterial ECMO, a flow set at the rate of $\mathrm{mL} / \mathrm{kg} / \mathrm{min}$ flow, is adequate.

Arterial blood gases, lactates, mixed venous saturation, pre- and postmembrane pressures are all used to monitor the systemic perfusion in a VA ECMO patient. The VA ECMO is started under a set of indications only (- Table 1). In pediatric, we use both high- and low-flow ECMO. However, there is paucity in literature about their risks. This study thus is undertaken to study the efficacy of low-flow ECMO.
DOI https://doi.org/ $10.1055 / \mathrm{s}-0041-1732796$ ISSN 2457-0206 (c) 2021. Official Publication of The Simulation Society (TSS), accredited by International Society of Cardiovascular Ultrasound (ISCU).

This is an open access article published by Thieme under the terms of the Creative Commons Attribution-NonDerivative-NonCommercial-License, permitting copying and reproduction so long as the original work is given appropriate credit. Contents may not be used for commercial purposes, or adapted, remixed, transformed or built upon. (https://creativecommons.org/licenses/by-nc-nd/4.0/).

Thieme Medical and Scientific Publishers Pvt. Ltd. A-12, 2nd Floor, Sector 2, Noida-201301 UP, India 
Table 1 Indications of ECMO in cardiac surgery patient

\begin{tabular}{|l|}
\hline$>$ Cardiogenic shock not responding to maximal intervention \\
\hline$>$ Intra-aortic balloon counter pulsation \\
\hline$>$ Global myocardial failure \\
\hline - Failure to wean from CPB \\
\hline > Temporary bridge to cardiac rest and recovery \\
\hline$>$ Volume/inotropes/vasoconstriction \\
\hline
\end{tabular}

Abbreviations: CPB, cardiopulmonary bypass; ECMO, extracorporeal membrane oxygenation.

\section{Methods}

In this retrospective analysis, data of 395 patients on low-flow integrated pediatric ECMO were analyzed. The VA ECMO was done at our institution to extend the boundaries of the primary arterial switch operation (ASO), in the transposition of great arteries (TGA), for total anomalous pulmonary venous connection (TAPVC) and anomalous left coronary artery pulmonary artery (ALCAPA), enumerating the advantages of low-flow ECMO support with the help of integrated ECMO circuit.

The ECMO circuit is made up of various components that were customized at the All India Institute of Medical Sciences (AIIMS) in the form of integrated circuit with low-cost ECMO cart having battery backup to support the transport of the patient in ICU. ECMO circuit can vary from simple to complex and may include a variety of blood flow and pressure monitors, continuous oximeter hemoglobin saturation, circuit access sites, and bridge connecting the venous access and arterial infusion limbs of the circuit.

Pediatric ECMO oxygenator (EUROSETS A.L.ONE ECMO PEDIATRIC Italy), which is Food and Drugs Administration (FDA) approved for15 days' use, was used. An integrated ECMO-CPB circuit with the Capiox sX-10 (TERUMO Corp. Japan) reservoir was used with bridge line to obtain arterial access; from the reservoir, it was connected to the Biomedicus (Italy) pump, which led to the oxygenator that was integrated with the heat exchanger. A hemoconcentrator was used intraoperatively in the circuit ( - Fig. $\mathbf{1})$.

\section{Perfusion Details during Surgery}

CPB is established by utilizing aortic cannula and venous cannula for superior vena cava (SVC) and inferior vena cava (IVC). The heart is arrested using either Delnido cardioplegia or St. Thomas cardioplegia and given manually to the aortic root. Patient was cooled to 30 to $32^{\circ} \mathrm{C}$. Mean arterial pressure (MAP) of $53 \pm 4 \mathrm{~mm} \mathrm{Hg}$ was maintained during the procedure. Topical temperature was maintained by using the Bair Hugger machine. Adequacy of oxygen supply to the tissues was monitored by using near infrared spectroscopy (NIRS) throughout the procedure as per protocol. Once the surgery was over, СPB circuit of venous reservoir was excluded from the circuit, and the drainage from the right atrial appendage was achieved by using straight venous cannula, while the aortic cannula remained same and the patient was shifted to ICU with open chest and skin closure over the venoarterial cannulation. In this way, the patient was shifted to the ICU with ECMO support

\section{ECMO Management in ICU}

Heparin infusion was started at $10 \mathrm{units} / \mathrm{kg} / \mathrm{hr}$ and titrated to maintain activated clotting time between 180 to 220 seconds. Hematocrit and platelet counts were maintained at more than $40 \%$ and more than 1,20000 , respectively, by packed red blood cell and platelet transfusions. On ECMO support, inotropes were tapered to maintain MAP of 40 to $50 \mathrm{~mm}$ $\mathrm{Hg}$ with a central venous pressure (CVP) left atrial pressure (LAP) of $<6 \mathrm{~mm} \mathrm{Hg}$. With maximal flow rates on ECMO $(125-150 \mathrm{~mL} / \mathrm{kg})$, the patient was ventilated with fraction of inspired oxygen $=21 \%$, respiratory rate $=10 / \mathrm{min}$, tidal volume $=6-8 \mathrm{ml} / \mathrm{kg}$, and positive end expiratory pressure $($ PEEP $)=5-6 \mathrm{~cm} \mathrm{H} 2 \mathrm{O}$ to prevent atelectasis. Body temperature was maintained at 36 to $37^{\circ} \mathrm{C}$ by the convection body warmer. The patient was monitored clinically and biochemically. Clinically, ECMO flow rates, CVP/LAP, heart rate (HR), mean arterial blood pressure (ABP), oxygen saturation, urine output, and temperature were monitored and maintained by appropriate intervention. Biochemically, hemogram, liver function test, renal function test, mixed venous oxygen saturation, and daily blood cultures (aerobic/anaerobic/fungal)
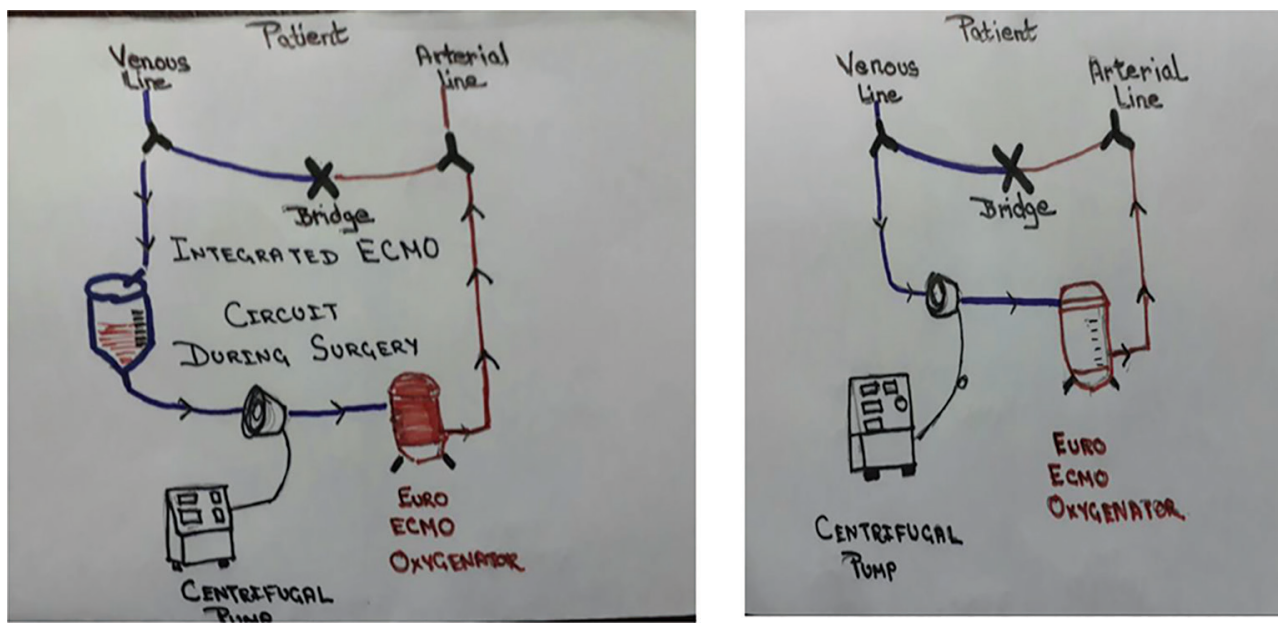

Fig. 1 Integrated ECMO circuit modified by All India Institute of Medical Sciences (AIIMS) perfusionist and AllMS team at present is shown. 
were monitored and maintained. A transthoracic echocardiogram was done after every 24 hours to evaluate myocardial contractility. Cranial ultrasound, through the anterior fontanel, was done every 24 hours to rule out intraventricular bleeding (-Fig. 2).

Weaning was initiated when all clinical, biochemical, and echocardiographic parameters were satisfactory. Weaning involved gradual decrease in flow by $10 \%$ every 1 to 2 hours to a flow of 30 to $40 \mathrm{~mL} / \mathrm{kg} / \mathrm{min}$, with maintenance of clinical parameters. A trial of 1 hour without ECMO support was given by clamping the arterial and venous cannulae and declamping the recirculation line. Once the child was able to maintain hemodynamic parameters, urine output (at least $1 \mathrm{ml} / \mathrm{kg} /$ hour), and arterial blood gases (minimal acidosis with satisfactory $\mathrm{PaO}_{2}$ and $\mathrm{PaCO}_{2}$ ), decannulation was done. Sternal closure was performed a day after decannulation and extubated accordingly. ${ }^{3}$

\section{Discussion}

The advantages integrated circuit ECMO include all the following: no time lag to initiate ECMO (even experienced personnel need 20 to 25 minutes to assemble and deair circuit), enables LV "re-training" under normoxemia and controlled loading, early initiation prevents end-organ damage by reducing chances of cardiac arrest and prolonged low-cardiac output, surgical asepsis and cost-effective, saving blood and blood products, especially in cases where patient has rare blood group, timely support rather than no support, safer outcomes with short period of ECMO, and less inotropes' requirement, thereby reducing toxic effect. ${ }^{4}$

Low-flow ECMO has its own limitations: It is good in cases where postcardiac patient lungs are good, that is, more flow through native lungs and less flow through artificial lungs; in other words, the oxygenator in case of VA ECMO.,5

In an ex-vivo model of ECMO, low-flow rate $(1.5 \mathrm{~L} / \mathrm{min})$ altered haemostatic parameters compared to high-flow ( $4 \mathrm{~L} /$ min). Observed differences in haemolysis, ristocetin-induced platelet aggregation, high-molecular-weight vWF multimers and clot formation time suggest an increased risk of bleeding complications. Since patients are often on ECMO for protracted periods, extended-duration studies are required to

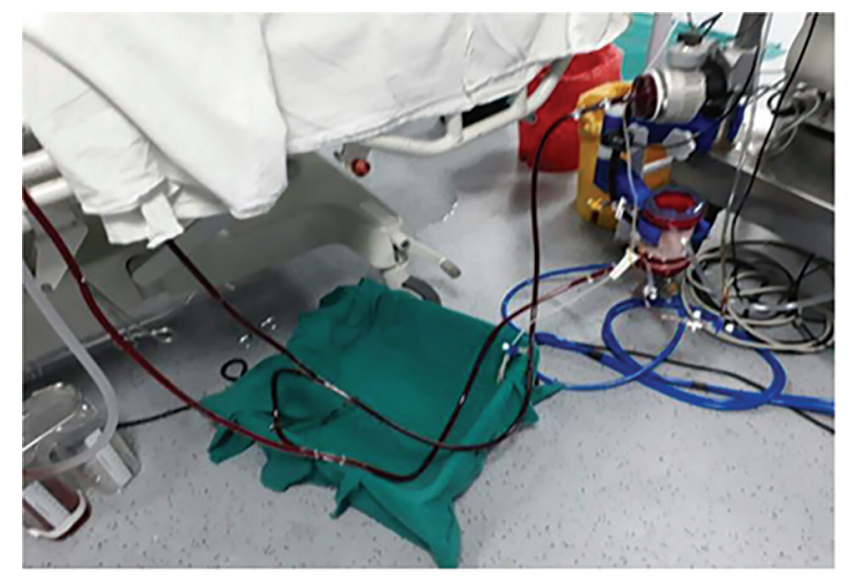

Fig. 2 ECMO setup in ICU characterise long-term ECMO-induced haemostatic changes. In our study, ECMO flows studied in VA ECMO alone. showed good results in the maintenance phase. ${ }^{6}$ Another, contradictory study in 2019 cautions ECMO intensivists against high flow and low flow rates while on ECMO. It is a in-vitro study, which informs ECMO specialists to avoid low and high blood flow that increases TF expression on leukocytes and EVs, which likely initiate clot formation. Interventions to decrease TF generated by ECMO may be an effective approach to decrease thrombosis. Tissue factor pathway inhibitor (TFPI), at 50 times more than the concentration in healthy adults, failed to suppress thrombin initiation in low flow and high flow circuits. ${ }^{7}$ With Current Rotary blood pumps, ECMO therapy for neonatal and paediatric patients uses comparable blood flow rates. Carbon dioxide removal, in venovenous ECMO is dependent upon sweep gas flow rate. A relatively low blood flow with high sweep gas flow is sufficient to remove upto $50 \%$ of $\mathrm{CO} 2$ produced by a patient. ${ }^{8}$ So eucapnia or low flow rates is easier to maintain on venovenous ECMO, than on venoarterial ECMO. ${ }^{9}$ The increase in sweep gas flow from 2 to $8 \mathrm{~L} /$ min increased normalized $\mathrm{CO} 2$ elimination from $35 \pm 5$ to $41 \pm 6$ with $900 \mathrm{~mL}$ blood flow/min, whereas with lower blood flow rates, any increase was less effective, levelling out at $4 \mathrm{~L}$ sweep gas flow $/ \mathrm{min}$. The influence of sweep gas flow on the $\mathrm{CO} 2$ removal capacity of ECCO2R systems depends predominantly on blood flow rate and membrane lung surface area. In this model, considerable $\mathrm{CO} 2$ removal occurred only with the larger membrane lung surface of $0.8 \mathrm{~m} 2$ and when blood flow rates of $\geq 900 \mathrm{~mL} / \mathrm{min}$ were used..$^{10}$

\section{Results}

Of the 250 patients analyzed for ECMO flow, 100 patients were on low-flow ECMO. A total of 100 patients on low-flow ECMO had a mortality of $40 \%$ (40 patients) vis-a-vis $70 \%$ for high-flow ECMO (-Tables 2-5). Table 2 indicates the outcomes by way of timing of intervention and low-flow ECMO with the help of integrated ECMO circuit. No ECMO support was given before surgery. Low-flow ECMO support had better outcome as compared with high-flow support. Table 3 indicates the outcome on diagnosis. Numbers of patients with TGA were more and so was the survival rate;

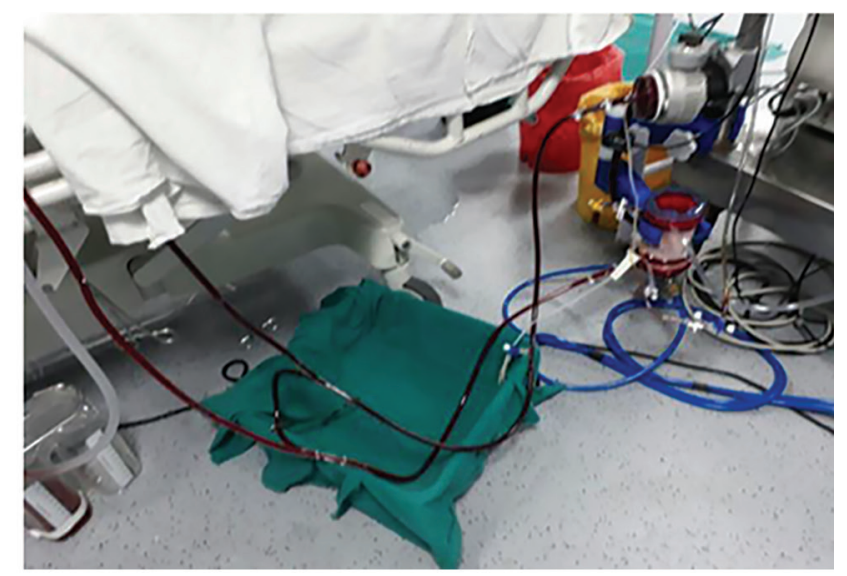


greater in the patients undergoing the arterial switch operation (ASO) for dextro-TGA. Table 4 Duration of ECMO support. As low-flow ECMO required less duration than highflow ECMO, therefore survival rate was better. Table 5 Patient median age and weight were in range of 29 days to 4 years and $3.5 \mathrm{~kg}$ (range of $2.1-12 \mathrm{~kg}$ ) approximately. Low flow was given up to $100 \mathrm{~mL} / \mathrm{min}$, but in case of high flow, $150 \mathrm{~mL} / \mathrm{kg}$ / min or more was given. This difference of 50 to $60 \mathrm{~mL}$ good outcome was in case of low-flow ECMO. Table 2 indicates the outcomes by way of timing of intervention and low-flow ECMO with the help of integrated ECMO circuit. No ECMO support was given before surgery. Low-flow ECMO support had better outcome as compared with high-flow support. Table 3 indicates the outcome on diagnosis. Numbers of patients with TGA were more and so was the survival rate; greater in the patients undergoing the arterial switch operation (ASO) for dextro-TGA. Table 4 Duration of ECMO support. As low-flow ECMO required less duration than highflow ECMO, therefore survival rate was better. Table 5 Patient median age and weight were in range of 29 days to 4 years and $3.5 \mathrm{~kg}$ (range of 2.1-12 kg) approximately. Low flow was given up to $100 \mathrm{~mL} / \mathrm{min}$, but in case of high flow, $150 \mathrm{~mL} / \mathrm{kg}$ / min or more was given. This difference of 50 to $60 \mathrm{~mL}$ good outcome was in case of low-flow ECMO.

Table 2 Low-flow and high-flow ECMO outcomes

\begin{tabular}{|l|l|l|}
\hline $\begin{array}{l}\text { Time of } \\
\text { intervention }\end{array}$ & Survived & Died \\
\hline Low-flow ECMO & 100 & 40 \\
\hline $\begin{array}{l}\text { Failure to wean } \\
\text { from CPB }\end{array}$ & 50 & 35 \\
\hline High-flow ECMO & 100 & 70 \\
\hline Total Number & 250 & 145 \\
\hline
\end{tabular}

Abbreviations: CPB, cardiopulmonary bypass; ECMO, extracorporeal membrane oxygenation.

Table 2 indicates the outcomes by way of timing of intervention and low-flow ECMO with the help of integrated ECMO circuit. No ECMO support was given before surgery. Low-flow ECMO support had better outcome as compared with high-flow support.

Table 3 Outcome by diagnosis

\begin{tabular}{|l|l|l|}
\hline Diagnosis & Survived & Died \\
\hline TGA & 120 & 85 \\
\hline ALCAPA & 100 & 40 \\
\hline TAPVC & 30 & 10 \\
\hline Total & 250 & 145 \\
\hline
\end{tabular}

Abbreviations: ALCAPA, anomalous left coronary artery pulmonary artery; TAPVC, total anomalous pulmonary venous connection; TGA, transposition of great arteries.

Table 3 indicates the outcome on diagnosis. Numbers of patients with TGA were more and so was the survival rate; greater in the patients undergoing the arterial switch operation (ASO) for dextro-TCA.
Table 4 Outcome by duration of ECMO run

\begin{tabular}{|l|l|l|}
\hline $\begin{array}{l}\text { Duration Of } \\
\text { ECMO run } \\
\text { (hours) }\end{array}$ & Survived & Died \\
\hline $\mathbf{2 4 - 4 8}$ & 120 & 100 \\
\hline $\mathbf{4 8 - 7 2}$ & 100 & 40 \\
\hline $\mathbf{> 7 2}$ & 30 & 5 \\
\hline Total & 250 & 145 \\
\hline
\end{tabular}

Table 4 Duration of ECMO support. As low-flow ECMO required less duration than high-flow ECMO, therefore survival rate was better.

Table 5 Total number of patients receiving ECMO support was around 250 in our study with a 10-year period (2011-2020)

\begin{tabular}{|l|l|l|}
\hline & Flow given & No. of patients \\
\hline Low-flow ECMO & $50 \mathrm{~mL} / \mathrm{kg} / \mathrm{min}$ & 60 patients \\
& $100 \mathrm{~mL} / \mathrm{kg} / \mathrm{min}$ & 40 patients \\
\hline High-flow ECMO & $150 \mathrm{~mL} / \mathrm{kg} / \mathrm{min}$ & 70 patients \\
& $200 \mathrm{~mL} / \mathrm{kg} / \mathrm{min}$ & 30 patients \\
\hline
\end{tabular}

Patient median age and weight were in range of 29 days to 4 years and $3.5 \mathrm{~kg}$ (range of $2.1-12 \mathrm{~kg}$ ) approximately. Low flow was given up to 100 $\mathrm{mL} / \mathrm{min}$, but in case of high flow, $150 \mathrm{~mL} / \mathrm{kg} / \mathrm{min}$ or more was given. This difference of 50 to $60 \mathrm{~mL}$ good outcome was in case of low-flow ECMO.

\section{Limitations of Our Study}

In select cases, the use of ECMO may result in patients' neurologically intact survival; however, the question remains as to whether this benefit is consistently observed in comparison to conventional care in the variety of settings in which it is used. Appropriate patient selection has been identified as key to such evaluation, and strategies at various stages of development have been proposed to do just that. Currently, these strategies are not incorporated into comparative evaluations of ECMO, as there exists no validated prognostic approach for identifying appropriate patients at ECMO initiation. Such entry criteria for ECMO have been described as a "moving target." Our study, therefore, focuses on the current use of ECMO, differentiated by indication on the flow rates. In this way, could not address the question of what patient populations, as defined by indication, might be best served by ECMO treatment. Still, an issue in future, will be more careful delineation of those patient populations in which ECMO remains an exercise in futility or a "bridge to nowhere." Although VA ECMO was developed to rescue patients with cardiogenic shock, the impact of ECMO on hemodynamics is often unpredictable and can lead to hemodynamic collapseThese limitations remain unanswered.

\section{Conclusion}

Management of pediatric patient requiring mechanical support after immediate surgery requires a well-coordinated multidisciplinary team of surgeon anesthetist, clinical perfusionist, nursing staff, and intensivist with preplanned techniques like integrated ECMO, which can lead to successful management of these scenarios. 
The integrated circuit ECMO may be a useful tool in patients with high predictability of postoperative mechanical support. Not only does it save time, but it also reduces the hesitancy to initiate ECMO; hence, cutting down the overall cost of surgery. The support provided by low-flow ECMO gives better outcomes as compared with high-flow ECMO support with respect to lesser duration and better survival rate with the help of integration ECMO.

\section{Conflict of Interest}

None declared.

\section{References}

1 Chauhan S, Subin S. Extracorporeal membrane oxygenation, an anesthesiologist's perspective: physiology and principles. Part 1. Ann Card Anaesth 2011;14(3):218-229

2 Chauhan S, Subin S. Extracorporeal membrane oxygenationan anaesthesiologist's perspective-Part II: clinical and technical consideration. Ann Card Anaesth 2012;15(1):69-82

3 Singh SP, Chauhan S, Bisoi AK, Sahoo M. Lactate clearance for initiating and weaning off extracorporeal membrane oxygenation in a child with regressed left ventricle after arterial switch operation. Ann Card Anaesth 2016;19(1): 188-191
4 Chauhan S, Pal N, Bisoi AK, Chauhan Y, Venugopal P. The integrated ECMO-CPB circuit. Anesthesiology 2007;107:A212

5 Bisoi AK, Sharma P, Chauhan S, et al. Primary arterial switch operation in children presenting late with d-transposition of great arteries and intact ventricular septum. When is it too late for a primary arterial switch operation? Eur J Cardiothorac Surg 2010;38(6):707-713

6 Katrina K. Ki, Margaret R. Passmore, Chris H. H. Chan, Maximilian V. Malfertheiner, Jonathon P. Fanning. Low flow rate alters haemostatic parameters in an ex-vivo extracorporeal membrane oxygenation circuit. Intensive Care Medicine Experimental 2019;7:1-15

7 Andrew D. Meyer, Anjana R. Rishmawi, Robin Kamucheka, Crystal Lafleur, Andriy I. Batchinsky. Effect of blood flow on platelets, leukocytes, and extracellular vesicles in thrombosis of simulated neonatal extracorporeal circulation. J Thromb Haemost. 2020;18:399-410.

8 Bein T., Weber F., Philipp A., et al. A new pumpless extracorporeal interventional lung assist in critical hypoxemia/hypercapnia. Critical Care Medicine. 2006;34(5):1372-1377

9 Terragni P., Maiolo G., Ranieri V. M. Role and potentials of lowflow $\mathrm{CO} 2$ removal system in mechanical ventilation. Current Opinion in Critical Care. 2012;18(1):93-98.

10 Strassmann, S., Merten, M., Schäfer, S. et al. Impact of sweep gas flow on extracorporeal CO2 removal (ECCO2R). ICMx 7, 17 (2019). https://doi.org/10.1186/s40635-019-0244-3 